\title{
Exploring Soil Bacterial Communities in Different Peanut-Cropping Sequences Using Multiple Molecular Approaches
}

\author{
Hari Sudini, Mark R. Liles, Covadonga R. Arias, Kira L. Bowen, and Robin N. Huettel
}

First, fourth, and fifth authors: Department of Entomology and Plant Pathology, second author: Department of Biological Sciences, and third author: Department of Fisheries and Allied Aquacultures, Auburn University, Auburn, AL 36849.

Accepted for publication 22 January 2011.

\section{ABSTRACT}

Sudini, H., Liles, M. R., Arias, C. R., Bowen, K. L., and Huettel, R. N. 2011. Exploring soil bacterial communities in different peanut-cropping sequences using multiple molecular approaches. Phytopathology 101:819-827.

Soil bacterial communities have significant influence on soilborne plant pathogens and, thus, crop health. The present study focuses on ribotyping soil bacterial communities in different peanut-cropping sequences in Alabama. The objective was to identify changes in microbial assemblages in response to cropping sequences that can play a role in managing soilborne plant pathogens in peanut. Four peanut-cropping sequences were sampled at the Wiregrass Research Station, Headland, AL in 2006 and 2007, including continuous peanut, 4 years of bahiagrass followed by peanut, peanut-cotton, and peanut-corn-cotton. Soil sampling was done at early and mid-season and at harvest. Bacterial community structure was assessed using ribosomal intergenic spacer analysis (RISA) combined with $16 \mathrm{~S}$ rRNA cloning and sequencing. RISA results indicated $>70 \%$ dissimilarities among different cropping sequences. However, $90 \%$ similarities were noticed among replicated plots of the same cropping sequences. Cropping sequences and time of soil sampling had considerable effect on soil microbial community structure. Bahiagrass rotation with peanut was found to have the highest bacterial diversity, as indicated by a high Shannon Weaver Diversity index. Overall, higher bacterial diversity was observed with bahiagrass and corn rotations compared with continuous peanut. The bacterial divisions Proteobacteria, Acidobacteria, Firmicutes, Bacteroidetes, and Actinomycetes were the predominant bacterial phyla found in all peanut-cropping sequences. The Proteobacteria taxa in these soils were negatively correlated with the abundance of members of division Firmicutes but, conversely, had a significant positive correlation with Gemmatimonadetes taxa. The prevalence of the division Actinomycetes was negatively correlated with the relative abundance of members of division Verrucomicrobia. These results indicate complex interactions among soil bacteria that are important contributors to crop health.

Additional keywords: soil microbial communities.
Soil microbial communities are dynamic systems that can be influenced by several edaphic factors as well as the type of plant species grown, agronomic practices, and chemicals used to control major biotic stresses. Within the soil microbial community, bacteria are critical to nutrient cycling and are the dominant organisms within soils in terms of relative abundance, with most soils containing $>10^{9}$ bacterial cells per gram of soil (31). Although some bacteria can cause plant disease, most are beneficial $(19,30)$. The bacterial populations in plant rhizospheres may contribute to crop health by mediating nutrient acquisition and by controlling the growth or activity of plant pathogens. Bacterial biological control of plant pathogens can be due to antibiosis, competition for nutrients, contribution toward induction of systemic resistance in hosts, and siderophore production $(23,25)$.

Peanut is an important cash crop in the southeastern United States and is affected by many soilborne and foliar diseases. However, aflatoxin contamination is a major threat to the peanut industry because this problem affects the quality of the crop and, thus, negatively impacts trade and crop profitability (15). Aflatoxins are produced by the Aspergillus flavus group of fungi (i.e., A. flavus and A. parasiticus) following invasion of peanut pods during preharvest and postharvest stages $(11,12)$. Aflatoxins are secondary metabolites which are carcinogenic, teratogenic, and hepatotoxic. The distribution of these aflatoxigenic fungi in

Corresponding author: H. Sudini; E-mail address: sudinhk@gmail.com

* The $e$-Xtra logo stands for "electronic extra" and indicates that Figures 2 to 5 appear in color online.

doi:10.1094/PHYTO-11-10-0310

(C) 2011 The American Phytopathological Society soils supporting the growth of peanut is largely dependent on the prevalence of antagonistic microflora, especially the bacterial community (21). The existing bacterial communities which play a pivotal role in reducing the pathogen load in soils are to be monitored and preserved so as to manage this soil-saprophytic $A$. flavus group of fungi toward a healthy peanut crop environment.

Bacterial communities in soils can be monitored through culture-dependent and -independent techniques. The culture-dependent methods include enumeration of bacterial cells on media followed by identification. These methods are biased in estimating the diversity and richness of bacterial taxa, given that many bacterial phyla that are abundant in soils (e.g., Acidobacteria) are poorly represented in culture-based phylogenetic surveys $(4,28)$. On the other hand, the culture-independent methods using nucleic acid-based identification and characterization can provide superior resolution without a cultivation bias and allow parallel processing of replicate soil samples, while still being subject to methodological biases inherent in DNA amplification that result in underestimation of diversity (40). Many techniques relying upon amplification of the evolutionarily conserved 16S rRNA gene have been applied to studies of soil microbial communities, such as denaturing gradient gel electrophoresis (DGGE), terminal restriction fragment length polymorphism, ribosomal intergenic spacer analysis (RISA), and 16S rDNA cloning, all of which are sometimes coupled with DNA sequencing $(6,14,16,28)$. These molecular techniques provide a rapid and highly reproducible means of estimating the microbial diversity in soils.

In this study, a census of bacterial populations in different peanut-cropping sequences was conducted through a combination of culture-independent techniques. The objective was to identify 
changes in the composition of soil bacterial communities among four different peanut-cropping sequences as well as within each cropping sequence over different sampling times using RISA and their implication on aflatoxin contamination of peanut. Although RISA provides a relatively high-resolution analysis of bacterial community structure and allows comparison of multiple soil samples, no phylogenetically informative data results from RISA band profiles. Therefore, to further refine the ribotype information obtained by RISA, 16S rRNA gene cloning and sequencing was also conducted on the total genomic DNA extracted for the RISA study to identify bacterial taxa present within soils in different cropping sequences.

\section{MATERIALS AND METHODS}

Site history and soil sampling. Soil samples were obtained from the Wiregrass Research and Extension Center, Headland, AL from a long-term rotation study. The rotation sequences used in this study were continuous peanut (P-P-P-P), peanut-cotton (Ct-P$\mathrm{Ct}-\mathrm{P})$, peanut-corn-cotton ( $\mathrm{P}-\mathrm{Cn}-\mathrm{Ct}-\mathrm{P})$, and continuous bahiagrass for 4 years followed by peanut (B-B-B-B-P). Rotation sequences were arranged in a randomized complete block design with four replications. Soil sampling was conducted early-season (June), mid-season (August), and at harvest (October) during each cropping season of 2006, 2007, and 2008. Five soil cores were taken randomly across each plot from the root zone in each replication. Samples were placed in a plastic bag and transferred in a cooler.

DNA extraction. Total genomic DNA was extracted from $10 \mathrm{~g}$ of soil using the Power Mac Soil kit from MoBio (MoBio Laboratories Inc., Carlsbad, CA) following the manufacturer's instructions. The DNA was extracted immediately after sampling in order to maintain uniformity for comparing the bacterial communities. The quality and quantity of extracted DNA was determined using a NanoDrop Spectrophotometer (Thermo Scientific). DNA stock solutions of $5 \mathrm{ng} / \mu \mathrm{l}$ were prepared and stored at $-80^{\circ} \mathrm{C}$ for downstream application.

RISA polymerase chain reaction. The bacterial ribosomal intergenic spacers were amplified using the primers internal transcribed spacer (ITS)F (5'-GTCGTAACAAGGTAGCCGTA-3') and ITSReub (5'-GCCAAGGCATCCACC-3') (9). The reaction mixture $(50 \mu$ total volume) for polymerase chain reaction (PCR) consisted of $5 \mu$ of $10 \times$ dilution buffer $(20 \mathrm{mM}$ Tris- $\mathrm{HCl}$, [pH 7.5], $100 \mathrm{mM} \mathrm{KCL}, 15 \mathrm{mM} \mathrm{MgCl} 2,1 \mathrm{~m} \mathrm{M}$ dithiothreitol, $0.1 \mathrm{mM}$ EDTA, 0.5\% Tween 20 [vol/vol], 0.5\% Nonidet P40 [vol/vol], and $50 \%$ glycerol [vol/vol]), $10 \mu \mathrm{M}$ dNTPs, $400 \mathrm{nM}$ ITSF primer, $200 \mathrm{nM}$ ITSReub primer, $200 \mathrm{nM}$ ITSReub primer 5' labeled with IRD700 fluorochrome (LI-COR, Lincoln, NE), 2 U of Taq polymerase (Promega Corp., Madison, WI), $5 \mu \mathrm{M} \mathrm{MgCl}_{2}$, and $20 \mu \mathrm{l}$ of template DNA $(\approx 100 \mathrm{ng})$. Amplification was performed in a Peltier thermal cycler (PTC 200; MJ Research) after a hot start at $94^{\circ} \mathrm{C}$ for $3 \mathrm{~min}$; followed by 30 cycles consisting of $94^{\circ} \mathrm{C}$ for $45 \mathrm{~s}, 55^{\circ} \mathrm{C}$ for $1 \mathrm{~min}$, and $68^{\circ} \mathrm{C}$ for $2 \mathrm{~min}$; and final extension of $7 \mathrm{~min}$ at $68^{\circ} \mathrm{C}$. The polyacrylamide gel was prepared by mixing $30 \mathrm{ml}$ of $5.5 \%$ LI-COR poly-acrylamide (KB plus; LI-COR), $200 \mu \mathrm{l}$ of $10 \%$ ammonium persulfate, and $20 \mu \mathrm{l}$ of $\mathrm{N}, \mathrm{N}, \mathrm{N}^{\prime}, \mathrm{N}^{\prime}-$ tetramethylethylenediamine. Each PCR product $(5 \mu \mathrm{l})$ was transferred to new tubes and $2.5 \mu$ of stop buffer was added (Blue Stop Solution; LI-COR). Amplified products were denatured at $98^{\circ} \mathrm{C}$ for $5 \mathrm{~min}$. The PCR products $(0.6$ to $0.8 \mu \mathrm{l})$ were electrophoresed on the NEN Global Edition IR2 DNA Analyzer (LICOR) following the manufacturer's instructions. RISA fragments were resolved on $5.5 \%$ polyacrylamide gels and run under denaturing conditions for $8 \mathrm{~h}$ at $1,500 \mathrm{~V}$ on a LI-COR 4300 DNA sequencer.

The RISA gel images were analyzed by the BIONUMERICS V. 5.0 software program. Levels of similarity between fingerprints were calculated with the Pearson product-moment correlation co- efficient $(r)$ after the banding patterns were subjected to conversion, normalization, and background subtraction with mathematical algorithms. Cluster analysis was performed with the unweighted pair-group method using average linkages (UPGMA) (2). Multidimensional scaling analysis (MDSA) was done to compare the clusters generated over different crop rotations as well as different sampling times.

16S rRNA cloning and sequencing. The genomic DNA extracted from soils sampled in June 2006 were PCR amplified using universal bacterial primers 27F (5'-AGAGTTTGAT CMTGGCTCAG-3') and 1492R (5'-TACGGHTACCTTGTTA CGACTT-3') targeting the 16S rRNA gene (26). PCR reaction components contained $25 \mu \mathrm{l}$ of $2 \times$ GoGreen (Promega Corp.), $400 \mathrm{nM}$ final concentration for each primer, and $50 \mathrm{ng}$ of template DNA in a final volume of $50 \mu \mathrm{l}$. To improve PCR, $0.5 \mu \mathrm{l}$ of concentrated bovine serum albumin at $10 \mathrm{mg} / \mathrm{ml}$ was added to the reaction mixture. Thermal cycling was initiated after DNA template was added at $95^{\circ} \mathrm{C}$ for a hot start; then, 30 cycles of amplification were performed at $95^{\circ} \mathrm{C}$ for $30 \mathrm{~s}, 55^{\circ} \mathrm{C}$ for $1 \mathrm{~min}$, and $72^{\circ} \mathrm{C}$ for $2 \mathrm{~min}$; and a final extension of $72^{\circ} \mathrm{C}$ for $5 \mathrm{~min}$. The amplification product was verified on a $1 \%$ agarose gel followed by ethidium bromide staining. The PCR product was purified using a Wizard SV Gel and PCR Clean-Up System (Promega Corp.) following the manufacturer's instructions.

The 16S rDNA amplicons were ligated into a TOPO-TA pCR2.1 vector (Invitrogen, Carlsbad, CA). After electroporation into Escherichia coli, the transformants were grown on Luria Bertani agar plates containing kanamycin at $25 \mu \mathrm{g} / \mathrm{ml}$. In total, 288 different rDNA gene clones from each soil sample were sequenced using rolling circle amplification of plasmid DNA and unidirectional sequencing with a vector primer (SymBio Corp., CA). The sequences were trimmed for quality at both ends using Sequencher 4.7 (Gene Codes Corp., Ann Arbor, MI). The trimmed rDNA gene sequences were compared with the GenBank $\mathrm{nr} / \mathrm{nt}$ database using the BLASTn search algorithm. Divisional level affiliation for each rDNA gene clone was annotated manually based upon the identity of the top cultured bacterial nearest neighbor from the BLASTn analysis.

Rarefaction curves and diversity indices. Rarefaction curves were constructed for all 16S rRNA gene libraries generated from four different peanut-cropping sequences at different distant percent identity levels. A multiple alignment of each trimmed rDNA gene sequence was performed using ClustalX, and a distance file was generated from ClustalX output. Distance-based operational taxonomic unit (OTU) and richness analysis was performed using the ClustalX distance matrix to construct the rarefaction curves (35). Sequence similarities of $97 \%$ (0.03 distant matrices) and $85 \%$ ( 0.15 distance matrices) were considered to distinguish the number of unique OTUs at approximate species and divisional levels for each rDNA clone library $(20,32)$.

The Shannon-Weaver diversity index $(H)$ for relative abundance of 16S rRNA at the divisional level was calculated based on $H=$ $-\Sigma p_{i} \ln (p i)$ and the Simpson index $(1-D)$ was also calculated by $1-D=1-\Sigma p_{i}^{2}$, where $p_{i}=$ the relative abundance of each group of organisms.

Physical evaluation of pods and aflatoxin estimation. Harvested pods were bulked and later sorted into different categories by visual examination for each replicated plot. In total, 150 pods were visually evaluated from each sample as being small or immature, rotten, discolored, or nematode damaged or having insect scars and holes, cracks, and visible A. flavus. Aflatoxin estimation for pod samples was carried out using Mycosep Multifunctional Cleanup Columns (Romer Labs, Inc., Washington, MO) in highperformance liquid chromatography according to Wilson and Romer (39).

Statistical analysis. Correlations were calculated among the abundance of bacterial groups and physical evaluation parameters of pods using the SAS statistical package (version 9.1.3; SAS 


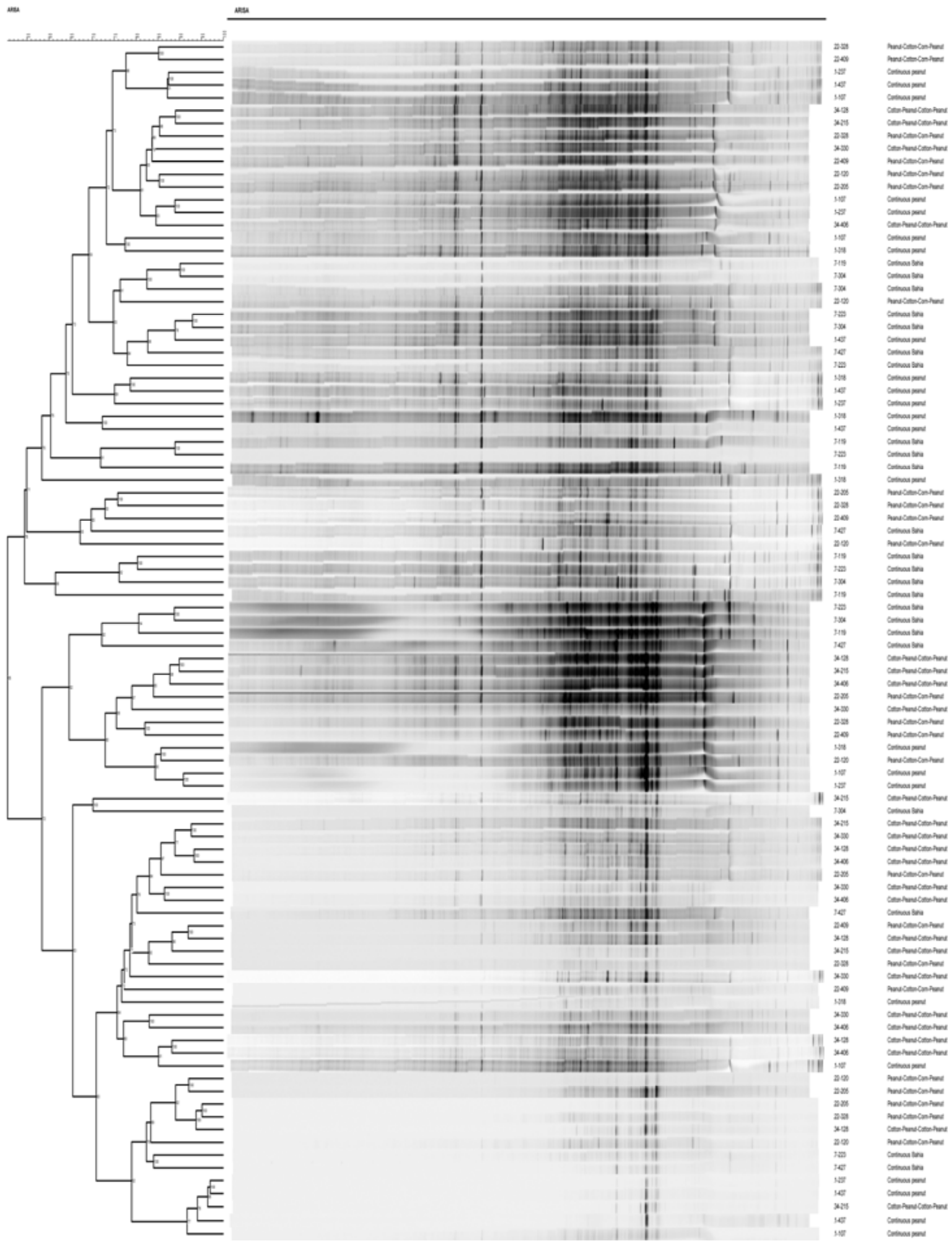

Fig. 1. Bacterial ribosomal intergenic spacer analysis patterns obtained from different peanut cropping sequences. Note: scale represents percent similarity calculated by the Pearson's product correlation. The dendrogram was constructed by using unweighted pair-group method with arithmetic mean 
Institute, Cary, NC). Because aflatoxins were not detected from any sample in 2008, these were not included in data comparisons.

\section{RESULTS}

Bacterial RISA profiles. The RISA profiles indicated significant similarities among community profiles of replicated plots

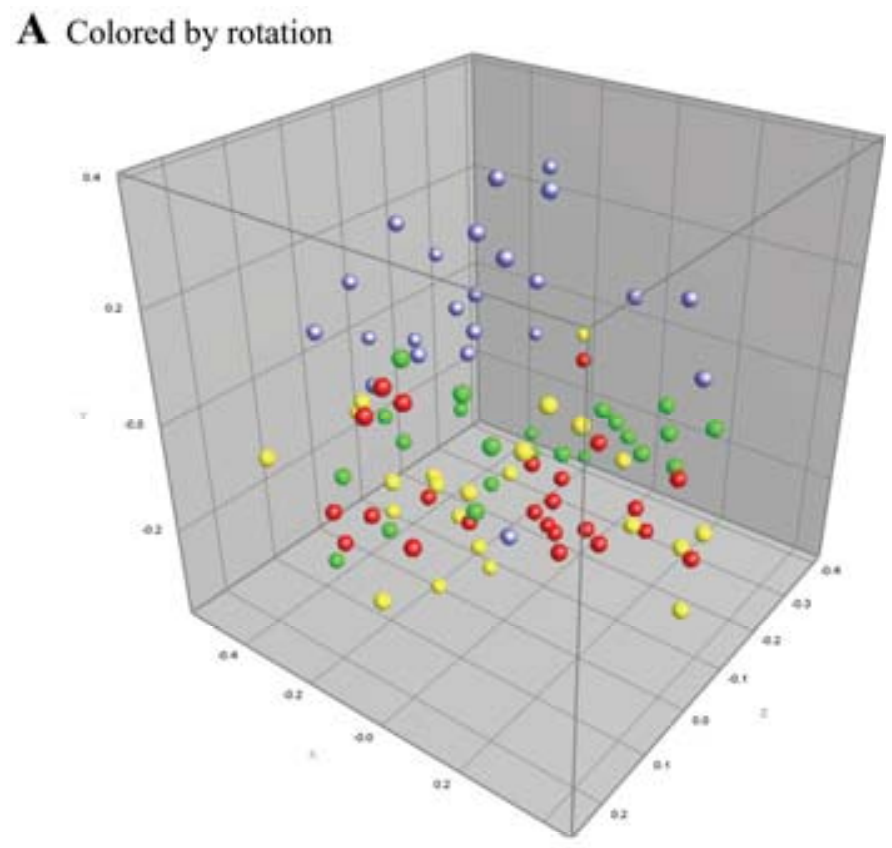

Continuous Peanut

Cotton-Peanut

4 yrs Continuous Bahiagrass + Peanuts

Peanut-Cotton-Corn

\section{B Colored by sampling time}

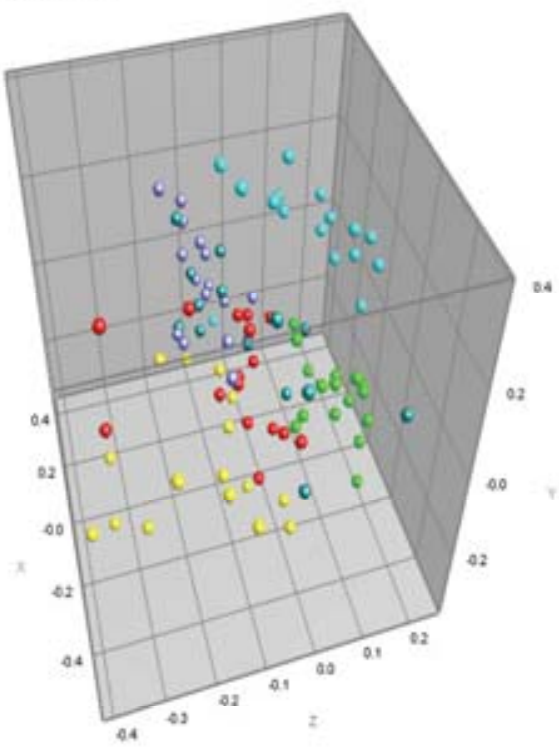

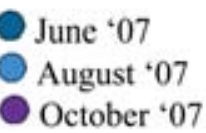

Fig. 2. Multidimensional scaling analysis of soil bacterial communities. A, Colored by rotation. B, Colored by sampling time. sampled from the same crop rotation (Fig. 1). Some common bands were observed among all crop rotations regardless of time of sampling and type of cropping sequence. In general, similarities within a range of 60 to $80 \%$ were observed among the plots of different cropping sequences in 2006 to 2007. RISA banding patterns from the continuous peanut-cropping system (P-P-P-P) indicated that there was $\approx 95 \%$ similarity in the plots that were sampled in October 2007 . However, $\approx 89 \%$ similarity was observed among the plots that were sampled during August and October 2006 and August 2007. In the case of 4 years of continuous bahiagrass followed by peanut (B-B-B-B-P), similarities of $88 \%$ were observed in plots that were sampled during August 2007. The banding pattern of the same rotation plots showed a marginal increase in similarity levels when sampled during October 2007 (90\% similarity). In the peanut-cotton rotation (Ct-P-Ct-P), for plots sampled in August 2006, the similarities were $92 \%$ when plots were sampled in August, and plots sampled in October 2006 had a similarity of $89 \%$. The peanutcorn-cotton (P-Cn-Ct-P) rotation plots sampled in August 2006 clustered at $85 \%$ similarity but showed $93 \%$ similarity when sampled during October 2007.

MDSA of RISA community profiles of different cropping sequences revealed that bacterial communities specific to each cropping system were generally clustered with a few outliers, indicating a strong impact of cropping system on soil bacterial community structure (Fig. 2A). However, greater similarities were observed according to sampling time than to cropping sequences in practice (Fig. 2B).

Relative abundance of bacterial phyla in different cropping sequences. Using BLASTn analysis, 288 16S rRNA gene sequences obtained from each soil rDNA gene library were sequenced and $\approx 240$ sequences from each sample were found to have sequence similarities that affiliated them with known bacterial divisions. Poor-quality sequences were removed from the analysis to prevent ambiguous phylogenies. Even though the sequences were affiliated with many bacterial phyla, five divisions within the domain Bacteria were found to be predominant among all the peanut-cropping sequences: Proteobacteria, Acidobacteria, Firmicutes, Bacteroidetes, and Actinobacteria (Fig. 3).

Among the bacterial divisions that were identified within the collection of sequences in the 16S rRNA gene libraries, the predominant gram-negative bacterial populations belonged to the division Proteobacteria (32\%), followed by Acidobacteria $(23.3 \%)$ and Bacteroidetes $(7.7 \%)$. Other gram-negative bacterial divisions (namely, Planctomycetes, Chloroflexi, Gemmatimonadetes, Nitrospirae, and Verrucomicrobia) were found at 1.5 to $3.2 \%$ of the total clones sequenced. The gram-positive bacterial divisions Firmicutes and Actinobacteria accounted for 13.8 and $7.5 \%$ of total clones, respectively. There was no significant difference $(P>0.05)$ among crop rotations with respect to the rRNA abundance in bacterial divisions. However, correlation analysis indicated that Proteobacteria populations were negatively correlated with Firmicutes populations $(r=-0.65$ and $P=0.006)$ (Fig. 4A) and positively correlated with Gemmatimonadetes $(r=$ 0.64 and $P=0.007)$. A similar negative correlation existed between Actinomycetes and Verrucomicrobia $(r=-0.51$ and $P=$ 0.04) (Fig. 4B).

Diversity indices and rarefaction curves. Among the cropping systems, diversity was slightly greater from rotation involving bahiagrass followed by peanut (B-B-B-B-P) as indicated by highest $H$ value $(5.42 \pm 0.33)$ over other cropping systems (Table 1). The remaining cropping systems are also rich in microbial diversity, with high $H$ values $(H>5.2)$. Richness and diversity of all these peanut soils is also indicated using Simpson's diversity index which falls near zero $(1-D \approx 0.24)$ and is an indication of a more heterogeneous nature with respect to microbial communities (Table 1). 
The rarefaction curves (data not shown) were constructed by comparing 16S rRNA sequences to determine the ribotype richness among different peanut-cropping sequences. These curves arbitrarily compare the bacterial diversity at different percent identities (e.g., 85 and $97 \%$ identity) to determine the degree of sampling exhaustiveness at each respective OTU. It is evident that, at 0.15 and 0.20 levels (i.e., 85 and $80 \%$ rDNA identity), the rarefaction curves have started to level off, indicating that the sampling is nearing saturation at these OTU cutoffs, corresponding roughly to bacterial division-level affiliation. However, the curves at the 0.03 and 0.05 level have a steep slope for all the cropping sequences, thus indicating that sampling was inadequate for assessing the soil bacterial diversity at finer phylogenetic resolution.

Physical evaluation of pods and aflatoxin estimation. Visual evaluation of peanut pods indicated a significant positive correlation between nematode damage and total aflatoxin contamination of pods ( $r=0.5663, P=0.0277$ ). Pod discoloration also had a significant positive correlation to total aflatoxin content of pods $(r=0.6613, P=0.0073)$. In addition, nematode damage to pods was significantly correlated to visible fungal contamination $(r=0.8042, P=0.0003)$ and to pod discoloration $(r=0.8878, P \leq$ $0.0001)$. However, no significant correlation existed between visual fungal contamination and total aflatoxin content in pods ( $r=0.2396, P=0.3896)$. Other contributing factors to either total aflatoxin content or aflatoxin B1 content included insect scars on pods $(r=0.3528, P=0.1971$ with B1), insect holes $(r=0.2015$, $P=0.4714$ with total aflatoxins), and insect pod cracks $(r=$ $0.1794, P=0.5223$ with total aflatoxins), and each of these were not significant.

Total aflatoxin levels were found to be greater in 2006 compared with 2007 in continuous peanut-cropping systems (Table 2). However, the predominant aflatoxin, B1, was found to be lower in 2006 than in 2007. The mean total aflatoxin content and B1 aflatoxin in continuous bahiagrass during 2007 was found to be 19.75 and 1.95 parts per billion ( $\mathrm{ppb}$ ), respectively. The total aflatoxin content in peanut-cotton rotation during 2006 was 11.73 ppb and B1 content was $\approx 2.53$ ppb during 2006, whereas no aflatoxins were detected in 2008. The total and B1 type aflatoxins were found to be zero in 2008 for all the cropping sequences.

Aflatoxin levels (both B1 and total aflatoxins) were comparatively higher in fields where peanut are grown as monoculture over other peanut fields that were rotated alternatively with cotton (data not shown). Both B1 and total aflatoxin contents decreased in bahiagrass-rotated fields of peanut when compared with fields where peanut was grown as a monoculture (Fig. 5).

\section{DISCUSSION}

The combined use of culture-independent techniques was applied to study the impact of long-term crop rotations on the diversity and richness of resident soil bacterial communities. RISA profiles of bacterial populations in this study revealed $>70 \%$ dissimilarities among cropping sequences. However, greater similarities in bacterial profiles $(\approx 90 \%)$ among replicated plots of the same cropping sequences were observed even though these replications in the field studies were located $150 \mathrm{~m}$ apart. These similarities among replicated plots of the same cropping sequence and dissimilarities among different cropping sequences are attributed to the diversity of crops grown in each cropping sequence along with peanut. The interaction of different plant species has been shown to influence the bacterial diversity that exists in soil, especially in the rhizosphere (27). The bacterial community structure in the rhizospheres of chickpea, rape, and sudangrass is a result of complex interaction between the soil type, plant species, and root zone location of these crops as determined through PCRDGGE (27). Plant type had relatively greater impact over soil type and plant age in determining the soil microbial community structure in clover, bean, and alfalfa (38). However, contradictory reports on the impact of plant and soil types on bacterial diversity have been documented in the past. For example, plant and soil effects are masked by the strong influence of other important practices that are followed in agricultural soils where bacterial community structure is mostly dictated by the agronomic practices in cultivated fields, abandoned fields from cultivation, and fields with no history of cultivation $(7,8)$.

MDSA of RISA profiles indicated close clustering of bacterial communities with respect to sampling time, whereas significant differences were observed with respect to the cropping sequence. Because planting time denotes the age of the crop in cultivation in a particular field, diversity in the present study with respect to sampling time is attributed to the crop age as well as the weather at that particular time. Chemical fertilizer applications impact nu-

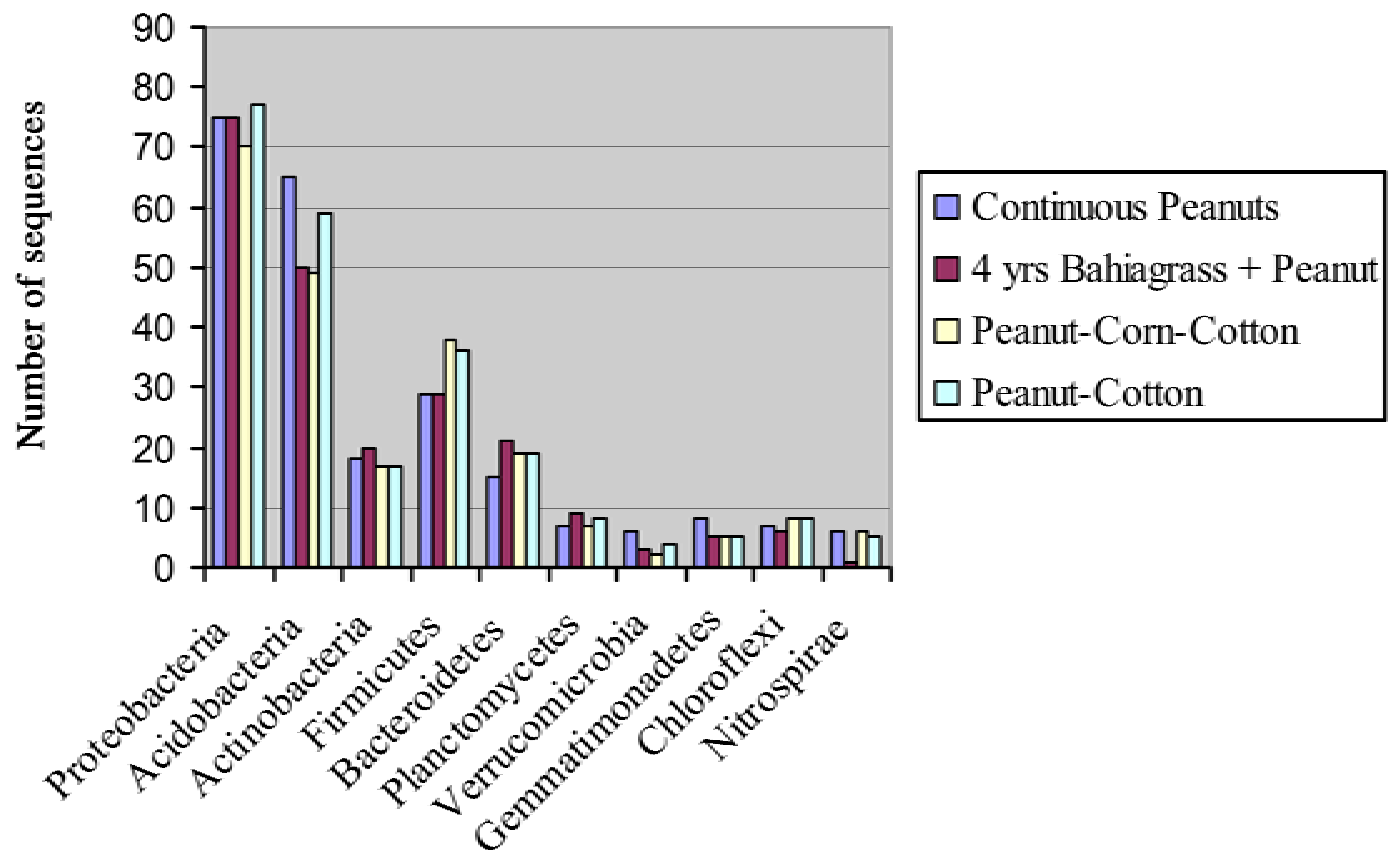

Fig. 3. Division-level affiliations of sequences from different peanut cropping systems as determined by $16 \mathrm{~S}$ rRNA library sequencing with homology to eubacterial sequences in the $\mathrm{nr} / \mathrm{nt}$ GenBank database. 
trient availability to crops; therefore, the soil bacterial community structure could be undergoing a dynamic shift (29). In our findings, sampling time had more impact on the clustering of community profiles and this change is attributed to the influence of soil environment factors such as soil moisture, soil temperature, soil nutrient status, and plant age at that particular point of time during a cropping season.

The results of cloning and sequencing revealed that the relative abundance of bacterial divisions based on 16S rRNA sequences is not significantly different among peanut-cropping sequences. However, in all rotations, there was an abundance of bacterial divisions Proteobacteria, Acidobacteria, Firmicutes, Bacteroidetes, and Actinomycetes over other bacterial divisions. This is in agreement with previous studies of soil agroecosystems $(7,8)$. The important bacterial genera that were consistently observed in this study among different times and cropping systems included Pseudomonas, Rhizobium, and Bacillus spp. Both Pseudomonas and Bacillus spp. include major plant growth promoting rhizobacteria that may suppress many soilborne diseases in crops (23, 24,37). Interestingly, correlations were observed in the relative abundance of certain bacterial phyla, with negative correlations observed between members of the Proteobacteria and Firmicute divisions and the Actinobacteria and Verrucomicrobia divisions; however, the populations of Proteobacteria had significant positive correlation with Gemmatimonadetes. These correlations between the relative abundance of different bacterial divisions may result from direct antagonistic or symbiotic interactions, or could be the consequence of complex indirect activities among the soil micro- and macrobiota. Interactions between rhizosphere bacteria and other microbes is a dynamic phenomenon in agricultural field soils, and such interactions can ultimately have a significant impact on crop health mediated by soilborne plant pathogens $(1,3,5,17)$. For example, the antagonistic effect of the Firmicute bacterium Pasteuria penetrans on root knot nematodes could alter plant-parasitic nematode populations $(10,34)$. In a long-term rotation study, the effect of cropping sequences might be masked by the dominant effect of management practices which include structural changes and depletion of soil nutrients (13).

The four peanut-cropping sequences selected for this investigation are under the influence of intensive agronomic practices. Continuous monitoring of these bacterial communities may help in determining the microbial interactions in soils supporting the growth of peanut under different cropping sequences. The bacterial diversity in all cropping sequences, as indicated by

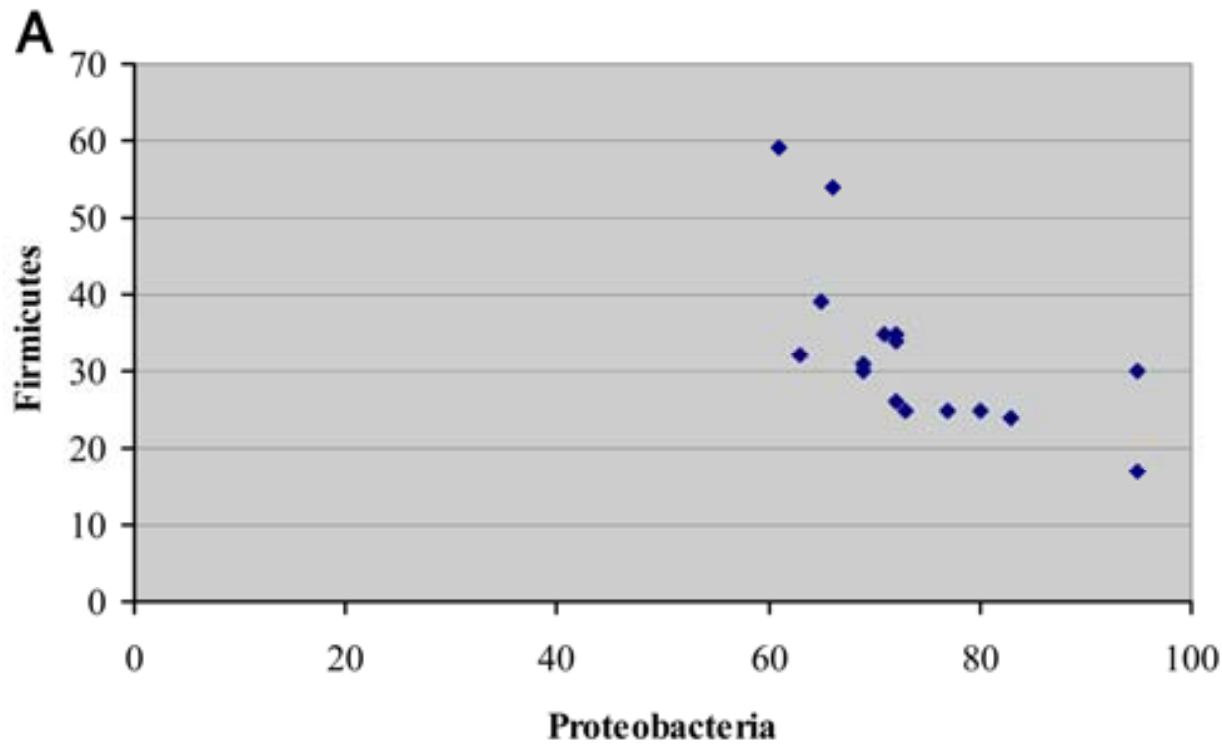

B

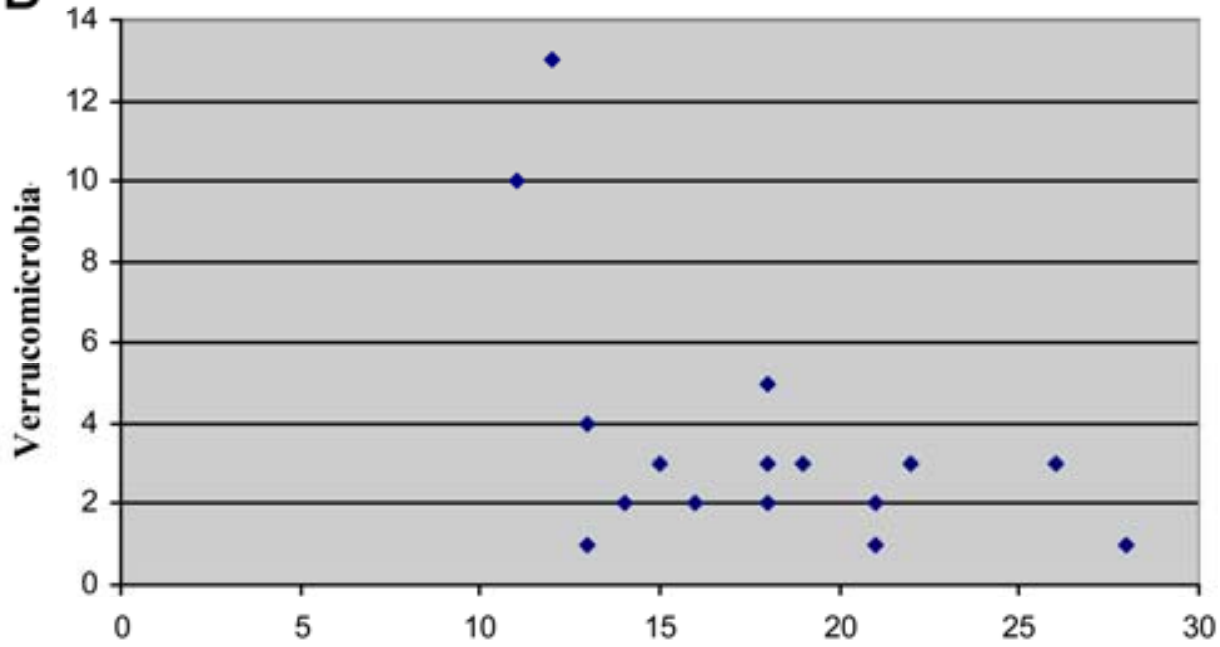

Actinobacteria

Fig. 4. Correlations between bacterial divisions based on 16S rRNA sequence similarities. A, Negative correlation between the abundance of Proteobacteria and Firmicutes $(r=-0.65, P=0.006)$. $\mathbf{B}$, Negative correlation between the abundance of Actinobacteria and Verrucomicrobia $(r=-0.51, P=0.04)$. 
Shannon-Weaver $(H)$ and Simpson $(1-D)$ indices, revealed a high diversity and heterogeneous nature of resident soil bacterial communities of different peanut ecosystems. Whereas the Simpson index represented heterogeneity among these cropping sequences, the Shannon-Weaver index projected no significant differences with respect to bacterial community diversity among the four cropping sequences under study. However, continuous bahiagrass rotation followed by peanut had slightly higher heterogeneity over other cropping sequences, thus indicating the role of bahiagrass in increasing soil microbial diversity. Based on our results, it can be inferred that bahiagrass cropping contributed significantly to reducing the A. flavus populations in soils (data not shown) when compared with other rotations in general and with peanut monocropping in particular. In an earlier study, bahiagrass, when used as a component in peanut-cotton rotations, was reported to en-

TABLE 1. Values for ecological diversity indices (DIs) of Shannon-Weaver $(H)$ and Simpson $(1-D)$ obtained using 16S rRNA gene relative abundance in different peanut-cropping sequences

\begin{tabular}{lcccc}
\hline & \multicolumn{4}{c}{ DI (average \pm standard deviation) for each cropping sequence ${ }^{\mathrm{a}}$} \\
\cline { 2 - 5 } DI & P-P-P-P & B-B-B-B-P & Ct-P-Ct-P & P-Cn-Ct-P \\
\hline$H$ & $5.24 \pm 0.19$ & $5.42 \pm 0.33$ & $5.27 \pm 0.11$ & $5.20 \pm 0.24$ \\
$1-D$ & $0.24 \pm 0.01$ & $0.23 \pm 0.02$ & $0.23 \pm 0.01$ & $0.23 \pm 0.01$ \\
\hline
\end{tabular}

${ }^{\text {a }}$ Data were calculated from four replicated plots of each cropping sequence: continuous peanut (P-P-P-P), continuous bahiagrass for 4 years followed by peanut (B-B-B-B-P), peanut-cotton (Ct-P-Ct-P), and peanut-corn-cotton (P-Cn-Ct-P).

TABLE 2. Aflatoxin levels in 2006 and 2007 from different peanut-cropping sequences $^{\mathrm{a}}$

\begin{tabular}{lccccc}
\hline & \multicolumn{3}{c}{ Aflatoxin levels (parts per billion) } \\
\cline { 2 - 3 } & \multicolumn{2}{c}{2006} & & \multicolumn{2}{c}{2007} \\
\cline { 2 - 3 } \cline { 5 - 6 } Type $^{\text {b }}$ & P-P-P-P & P-Ct-P-Ct & & P-P-P-P & B-B-B-B-P \\
\hline B1 & 6.9 & 2.533 & & 2.8282 & 1.9527 \\
B2 & 4.375 & 3.444 & & 26.3397 & 2.0845 \\
G1 & 0 & 5.747 & & 5.137 & 9.72 \\
G2 & 8.7513 & 0 & & 7.469 & 5.8822 \\
Total & 20.026 & 11.72 & & 41.75 & 19.75 \\
\hline
\end{tabular}

a Cropping sequences: continuous peanut (P-P-P-P), peanut-cotton (P-Ct-P$\mathrm{Ct}$ ), and continuous bahiagrass for 4 years followed by peanut (B-B-B-B-P). ${ }^{b}$ Type of aflatoxin. hance root biomass of cotton and peanut crops in subsequent years, thus increasing yields (22). Further, bahiagrass cultivation also is beneficial in reducing population levels of deleterious soil fauna such as Meloidogyne arenaria, the peanut root knot nematode, when included in a cropping sequence at least once every 2 years (22). Bahiagrass, when used as a long-term rotation, has the ability to improve beneficial soil microflora and may reduce the impact of soilborne diseases in peanut among different rotations practiced with corn and cotton (18). Rarefaction curves for all the cropping sequences denoted the inadequacy of sampling to determine the full extent of soil bacterial diversity and richness. The tremendous diversity of soil microbial taxa precludes an exhaustive analysis of rDNA sequences for each of the cropping sequences. Further sampling refinement and sequencing intensity (e.g., pyrosequencing) would be needed to exhaustively sample the bacterial diversity in these soils.

Arbitrary evaluation of pods from sampled plots for estimating the influence of different factors on aflatoxin contamination yielded interesting results. In the present study, a significant positive correlation was obtained between nematode infestation of pods with visual fungal contamination as well as with total aflatoxin contamination. Both of these factors were found to influence the total aflatoxin content of pods directly. In addition, the total aflatoxin content is indirectly being influenced by both pod discoloration and visual fungal contamination on pod surfaces. Pod discoloration has direct influence on aflatoxin contamination as well as on nematode damage, which further has direct influence on total aflatoxins. None of the other factors that are visualized have significant influence on pod aflatoxin contents. Pod damage due to nematode infestation might make pods prone to fungal attack and subsequent aflatoxin contamination. Timper et al. (36), while working on the relationship between peanut aflatoxins and nematode damage, reported that aflatoxins occurred more frequently in pods that had more nematode galls. Nematode infestation of pods may have provided sites by which the A. flavus in the soil gained entry, and this subsequently led to toxin contamination. However, a combination of factors may play a role in aflatoxin contamination such as nematode infestation, insect damage, and pod cracks that are induced by drought stress during the maturity periods (36). Nematode infestation of pods may also lead to impaired root functioning, thereby making the plants predisposed to drought stress. Sanders et al. (33) reported that drought stress around the pod zone predisposes peanut to aflatoxin contamination.

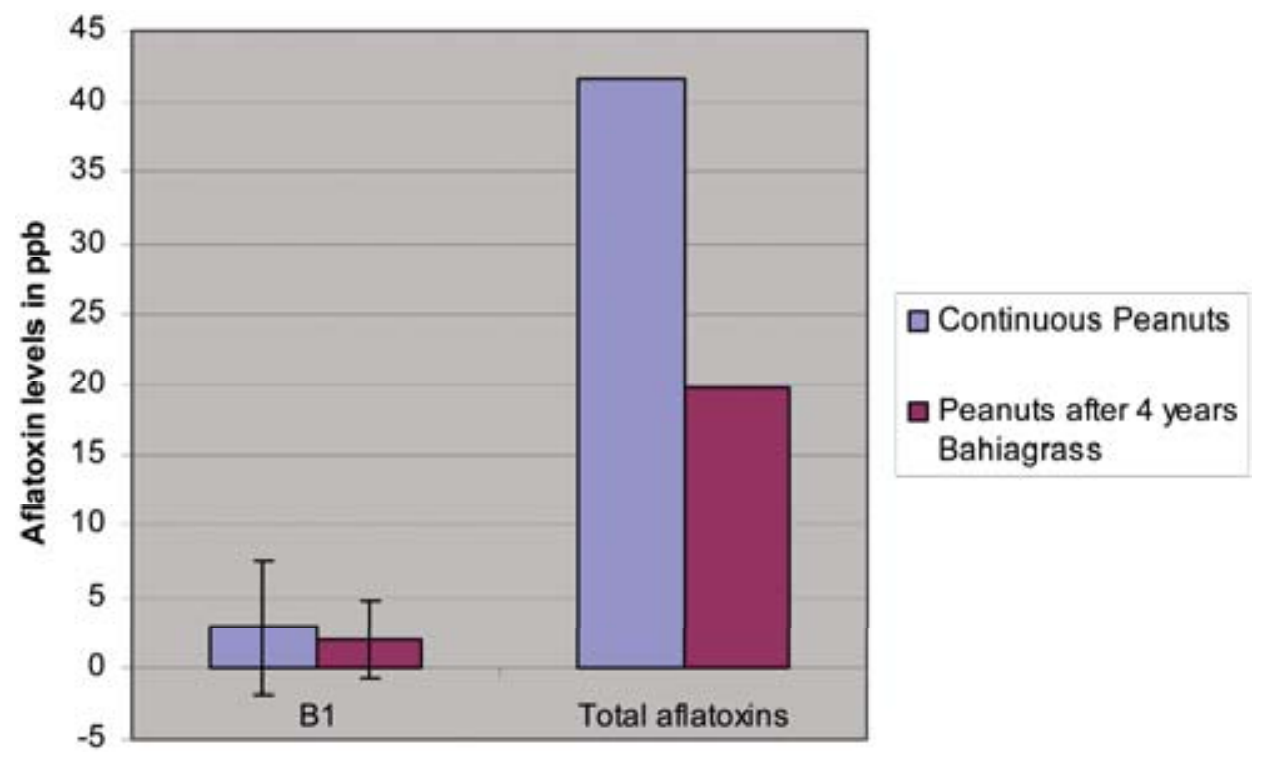

Fig. 5. Effect of bahiagrass rotation in peanut fields on pod aflatoxin contamination (parts per billion [ppb]) during 2007. 
Although we did not detect substantial differences in aflatoxin contamination levels between rotation sequences, similar trends were seen. Specifically, decreases in B1 and total aflatoxin levels were consistently noted when peanut was cropped following several years of bahiagrass. However, population dynamics of both $A$. flavus and $A$. parasiticus should be worked out in parallel. In addition, it needs to be kept in mind that results will vary depending upon the population levels of toxigenic and atoxigenic strains of these fungi. Trends from both experiments showed that bahiagrass rotation in peanut fields substantially reduced aflatoxin levels compared with peanut fields that are rotated with cotton, which is the most frequently used rotation system in the southeastern United States. In order to maintain crop health as well as soil health, sod-based crop rotation is always preferable instead of monocropping of peanut which, in turn, mitigates the effect of aflatoxin contamination in peanut.

This research was undertaken as an initial step toward developing a better understanding of the effects and interactions of different peanut-cropping sequences on soil microbial communities and to determine practical ways to potentially manipulate the soil microbial environment to provide improved crop health and productivity in sustainable agriculture. Monitoring of A. flavus populations in different peanut-cropping sequences and determining microbial community structure in these soils must be done at regular intervals so as to determine whether these can be manipulated to reduce aflatoxin contamination in peanut. For that reason, precise, high-resolution DNA fingerprinting methods were useful for constant monitoring of changes in microbial groups at a finer scale. Based on these community profiles obtained through molecular fingerprinting methods, cropping sequences can be determined to ameliorate the soil microbial community structures in favor of beneficial microflora in peanut soils for successful management of the aflatoxin problem and other soilborne pathogens in peanut. With further studies, we hope to identify more specific changes and characteristics of soil bacterial communities associated with particular peanut-cropping sequences and to relate these changes to effects on soilborne disease management and, thereby, crop health and productivity.

\section{ACKNOWLEDGMENTS}

We thank O. Olivares-Fuster of Fisheries and Allied Aquacultures department for his assistance in this project.

\section{LITERATURE CITED}

1. Andrade, G., Mihara, K. L., Linderman, R. G., and Bethlenfalvay, G. J. 1997. Bacteria from rhizosphere and hyphosphere soils of different arbuscular-mycorrhizal fungi. Plant Soil 192:71-79.

2. Arias, C. R., Welker, T. L., Shoemaker, C. A., Abernathy, J. W., and Klesius, P. H. 2004. Genetic fingerprinting of Flavobacterium columnare isolates from cultured fish. J. Appl. Microbiol. 97:421-428.

3. Azcon-Aguilar, C., and Barea, J. M. 1996. Arbuscular mycorrhizas and biological control of soil-borne plant pathogens-an overview of the mechanisms involved. Mycorrhiza 6:457-464.

4. Barns, S. M., Takala, S. L., and Kuske, C. R. 1999. Wide distribution and diversity of members of the bacterial kingdom Acidobacterium in the environment. Appl. Environ. Microbiol. 65:1731-1737.

5. Bianciotto, V., Minerdi, D., Perotto, S., and Bonfante, P. 1996. Cellular interactions between arbuscular mycorrhizal fungi and rhizosphere bacteria. Protoplasma 193:123-131.

6. Borneman, J., and Triplett, E. W. 1997. Molecular microbial diversity in soils from eastern Amazonia: Evidence for unusual micro-organisms and microbial population shifts associated with deforestation. Appl. Environ. Microbiol. 63:2647-2653.

7. Buckley, D. H., and Schmidt, T. M. 2001. The structure of microbial communities in soil and the lasting impact of cultivation. Microb. Ecol. 42:11-21.

8. Buckley, D. H., and Schmidt, T. M. 2003. Diversity and dynamics of microbial communities in soils from agro-ecosystems. Environ. Microbiol. 5:441-452.

9. Cardinale, M., Brusetti, L., Quatrini, P., Borin, S., Puglia, A. M., Rizzi,
A., Zanardini, E., Sorlini, C., Corselli, C., and Daffonchio, D. 2004. Comparison of different primer sets for use in automated ribosomal intergenic spacer analysis of complex bacterial communities. Appl. Environ. Microbiol. 70:6147-6156.

10. Chen, Z. X., and Dickson, D. W. 1998. Review of Pasteuria penetrans: Biology, ecology, and biological control potential. J. Nematol. 30:313340 .

11. Cole, R. J., Dorner, J. W., and Holbrook, C. C. 1995. Advances in mycotoxin elimination and resistance. Pages 456-474 in: Advances in Peanut Science. H. T. Stalker and H. E. Pattee, eds. American Peanut Research and Education Society, Stillwater, OK.

12. Dorner, J. W. 2008. Management and prevention of mycotoxins in peanuts. Food Addit. Contam. 25:203-208.

13. Drinkwater, L. E., Wagoner, P., and Sarrantonio, M. 1998. Legume based cropping systems have reduced carbon and nitrogen losses. Nature 396:262-265.

14. Engelen, B., Meinken, K., Witzingerode, F., Heuer, H., Malkomes, P. H., and Backhaus, H. 1998. Monitoring impact of a pesticide treatment on bacterial soil communities by metabolic and genetic fingerprint in addition to conventional testing procedures. Appl. Environ. Microbiol. 64:2814-2821.

15. Felicia, W., Yan, Li., and Deepak, B. 2008. Cost-effectiveness of aflatoxin control methods: Economic incentives. Toxin Rev. 27:203-225.

16. Fisher, M. M., and Triplett, E. W. 1999. Automated approach for ribosomal intergenic spacer analysis of microbial diversity and its application to freshwater bacterial communities. Appl. Environ. Microbiol. 65:4630-4636.

17. Garbaye, J. 1994. Helper bacteria - a new dimension to the mycorrhizal symbiosis. New Phytol. 128:197-210.

18. Hagan, A. K., Campbell, L. H., Weeks, J. R., Rivas-Davila, M. E., and Gamble, B. 2003. Impact of bahiagrass, cotton, and corn cropping frequency on the severity of diseases of peanut. In: Proc. Sod Based Cropping Syst. Conf. North Florida Research and Education CenterQuincy, University of Florida.

19. Higa, T. 1991. Effective microorganisms: A biotechnology for mankind. Pages 8-14 in: Proc. First Int. Conf. Kyusei Nature Farming. J. F. Parr, S. B. Hornick, and C. E. Whitman, ed. U. S. Dep. Agric. Washington, DC.

20. Hugenholtz, P., Goebel, B. M., and Pace, N. R. 1998. Impact of cultureindependent studies on the emerging phylogenetic view of bacterial diversity. J. Bacteriol. 180:4765-4774.

21. Jeffrey, D. P., Teresa, L. O. K., and Hameed, K. A. 2008. Microbial interactions with mycotoxigenic fungi and mycotoxins. Toxin Rev. 27:261-285

22. Katsvairo, T. W., Wright, D. L., Marois, J. J., Hartzog, D. L., Balkcom, K. B., Wiatrak, P. P., and Rich, J. R. 2007. Performance of peanut and cotton in a bahiagrass cropping system. Agron. J. 99:1245-1251.

23. Kloepper, J. W., Leong, J., Teintze, M., and Schroth, M. N. 1980. Enhanced plant-growth by siderophores produced by plant growth promoting rhizobacteria. Nature 286:885-886.

24. Kloepper, J. W., Lifshitz, R., and Schroth, M. N. 1988. Pseudomonas inoculants to benefit plant production. Pages 60-64 in: ISI Atlas of Science. Institute for Scientific Information, Philadelphia.

25. Kloepper, J. W., McInroy, J. A., and Bowen, K. L. 1992. Comparative identification by fatty acid analysis of soil, rhizosphere, and geocarposphere bacteria of peanut (Arachis hypogaea L). Plant Soil 139:85-90.

26. Lane, D. J. 1991. 16S/23S rRNA sequencing. Pages 115-175 in: Nucleic Acid Techniques in Bacterial Systematics. E. Stackebrandt and M. Goodfellow, eds. John Wiley and Sons, New York.

27. Marschner, P., Yang, C. H., Lieberei, R., and Crowley, D. E. 2001. Soil and plant specific effects on bacterial community composition in the rhizosphere. Soil Biol. Biochem. 33:1437-1445.

28. Ovreas, L., and Torsvik, V. 1998. Microbial diversity and community structure in two different agricultural soil communities. Microb. Ecol. 36:303-315

29. Parham, J. A., Deng, S. P., Da, H. N., Sun, H. Y., and Raun, W. R. 2003. Long-term cattle manure application in soil. II. Effect on soil microbial populations and community structure. Biol. Fertil. Soils 38:209-215.

30. Parr, J. F., and Hornick, S. B. 1994. Assessment of the Third International Conference on Kyusei Nature Farming: Round Table Discussion by USDA Scientists. Nature Farming Research and Development Foundation, Lompoc, CA.

31. Price, P. W. 1988. An overview of organismal interactions in ecosystems in evolutionary and ecological time. Agric. Ecosyst. Environ. 24:369-377.

32. Sait, M., Hugenholtz, P., and Janssen, P. H. 2002. Cultivation of globally distributed soil bacteria from phylogenetic lineages previously only detected in cultivation-independent surveys. Environ. Microbiol. 4:654666.

33. Sanders, T. H., Cole, R. J., Blankenship, P. D., and Dorner, J. W. 1993. Aflatoxin contamination of peanuts from plants drought stressed in pod or 
root zones. Peanut Sci. 20:5-8.

34. Sayer, R. M., and Starr, M. P. 1988. Bacterial diseases and antagonism of nematodes. Pages 59-101 in: Diseases of Nematodes. G. O. Poinar, Jr. and H. B. Jonson, eds. CRC Press, Boca Raton FL.

35. Schloss, P. D., and Handelsman, J. 2005. Introducing DOTUR, a computer program for defining operational taxonomic units and estimating species richness. Appl. Environ. Microbiol. 71:1501-1506.

36. Timper, P., Wilson, D. M., Holbrook, C. C., and Maw, B. W. 2004. Relationship between Meloidogyne arenaria and aflatoxin contamination in peanut. J. Nematol. 36:167-170.

37. Weller, D. M. 1988. Biological control of soilborne plant pathogens in the rhizosphere with bacteria. Annu. Rev. Phytopathol. 26:379-407.

38. Wieland, G., Neumann, R., and Backhaus, H. 2001. Variation of microbial communities in soil, rhizosphere and rhizoplane in response to crop species, soil type and crop development. Appl. Environ. Microbiol. 67:5849-5854.

39. Wilson, T. J., and Romer, T. R. 1991. Use of the Mycosep Multifunctional Cleanup Column for liquid chromatographic determination of aflatoxins in agricultural products. J. Assoc. Off. Anal. Chem. 74:951-956.

40. Wintzingerode, F., Gobel, U. B., and Stackebrandt, E. 1997. Determination of microbial diversity in environmental samples: Pitfalls of PCRbased rRNA analysis. FEMS Microbiol. Rev. 21:213-229. 